\title{
Design and synthesis of polycyclic sulfones via Diels-Alder reaction and ring-rearrangement metathesis as key steps
}

\author{
Sambasivarao Kotha* and Rama Gunta
}

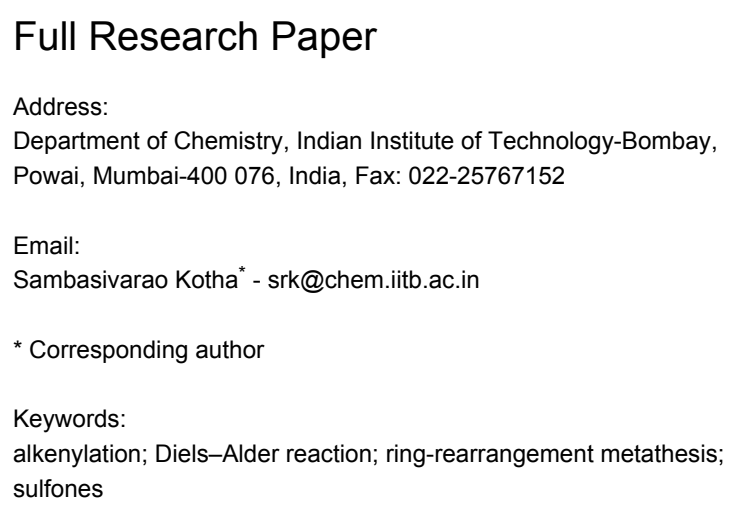

\author{
Beilstein J. Org. Chem. 2015, 11, 1373-1378. \\ doi:10.3762/bjoc.11.148 \\ Received: 16 April 2015 \\ Accepted: 20 July 2015 \\ Published: 06 August 2015 \\ This article is part of the Thematic Series "Progress in metathesis \\ chemistry II". \\ Guest Editor: K. Grela
}

(c) 2015 Kotha and Gunta; licensee Beilstein-Institut.

License and terms: see end of document.

\begin{abstract}
Here, we describe a new and simple synthetic strategy to various polycyclic sulfones via Diels-Alder reaction and ring-rearrangement metathesis (RRM) as the key steps. This approach delivers tri- and tetracyclic sulfones with six $(n=1)$, seven $(n=2)$ or eightmembered $(n=3)$ fused-ring systems containing trans-ring junctions unlike the conventional all cis-ring junctions generally obtained during the RRM sequence. Interestingly the starting materials used are simple and commercially available.
\end{abstract}

\section{Introduction}

Sulfones [1-8] are popular building blocks [9] in organic synthesis. They are also useful substrates for the Ramberg-Bäcklund reaction [10] and they can be alkylated via carbanion chemistry. Moreover, they are suitable synthons in Diels-Alder (DA) reactions [11-14]. In view of various applications of sulfone derivatives, we envisioned a new synthetic strategy based on ring-rearrangement metathesis (RRM) as a key step. It is worth mentioning that the RRM strategy [15-23] with a variety of substrates affords intricate products that are inaccessible by conventional retrosynthetic routes. Several bicyclo[2.2.1]heptane systems [24-26] are known to undergo RRM. However, in almost all instances the products produced are cis-configured at the ring junctions. The main driving force for the RRM of these systems is the release of ring strain. The configuration is transferred from the starting material to the product. In connection with our interest to design new polycycles by RRM [27,28] as a key step, here we conceive unique examples where cis and trans ring junctions are produced in the RRM reactions.

\section{Results and Discussion \\ Strategy}

Our retrosynthetic strategy to diverse sulfone derivatives is shown in Figure 1. The target sulfone derivatives $\mathbf{1}$ could be 
synthesized from the functionalized tricyclic sulfone $\mathbf{2}$ by RRM sequence. The sulfone 2 may be prepared from the dimesylate 3, which in turn, can be assembled from the known anhydride 4 via reduction followed by mesylation of the resulting diol. Compound 4 could be prepared via DA reaction starting with freshly cracked cyclopentadiene and maleic anhydride (Figure 1).

To realize the strategy shown in Figure 1, we started with the preparation of the known compound 4 [29,30]. Later, the DA adduct 4 was reduced with $\mathrm{LiAlH}_{4}$ to deliver the corresponding diol (95\%) [31], which was subsequently treated with methanesulfonyl chloride in the presence of triethylamine as a base to obtain the dimesylate 3 ( $89 \%$ ). Next, compound 3 was subjected to a cyclization reaction by treating with sodium sulfide nonahydrate $\left(\mathrm{Na}_{2} \mathrm{~S} \cdot 9 \mathrm{H}_{2} \mathrm{O}\right)$ using $20 \%$ Aliquat ${ }^{\circledR} 336$ as a phase-transfer catalyst (PTC) to produce the known sulfide $\mathbf{5}$ $(83 \%)$ [31].

Having the sulfide $\mathbf{5}$ in hand, our next task was to prepare sulfone 6. In this regard, Trost and Curran [32] have reported the conversion of sulfides to sulfones in the presence of other common functional groups such as olefins by reacting with the oxidizing agent, potassium hydrogen persulfate $\left(\mathrm{KHSO}_{5}\right.$, commercially available as Oxone ${ }^{\circledR}$ ) in aqueous methanol. Equipped with this information, oxidation of compound 5 was attempted under similar reaction conditions to get the desired sulfone 6 [33] (Scheme 1, Table 1).

Initially, when the reaction was carried out at $0{ }^{\circ} \mathrm{C}$, the epoxy sulfone 7 was the major product (Table 1, entry 1). However, after a considerable amount of experimentation (Table 1), the desired sulfone 6 has been produced in $89 \%$ yield (Table 1, entry 2) but it was not possible to eliminate the formation of the epoxy sulfone 7 .

Next, our efforts were directed towards the synthesis of various alkenylated sulfone derivatives. In this regard, Bloch and co-workers reported a useful preparation of monoallylated sulfone 8a [34]. To this end, we carried out the allylation of sulfone 6 with allyl bromide (1.2 equiv) and $n$-BuLi (2.7 equiv) at $-75{ }^{\circ} \mathrm{C}$ to $r$. The monoallylated sulfone 8 a was obtained in $22 \%$ yield and the diallylated sulfone $2 \mathrm{a}$ in $5 \%$ yield. Also, $25 \%$ of the starting material was recovered. To optimize the yield of diallylated sulfone $\mathbf{2 a}$ various conditions were studied (e.g., NaH and LDA). In this regard, increasing the
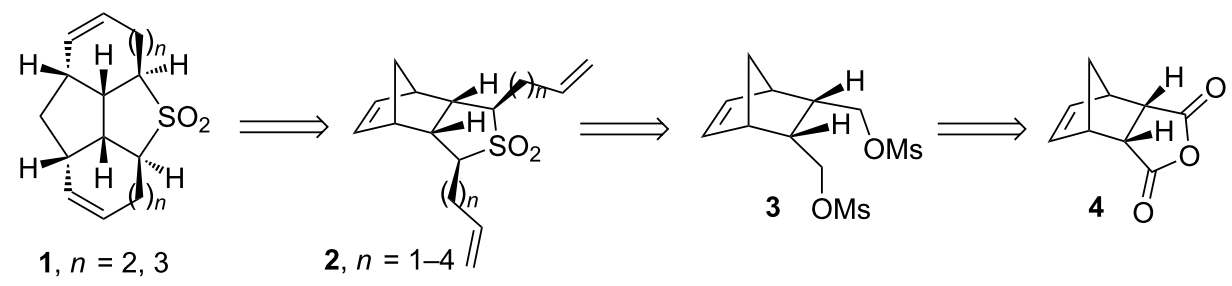

Figure 1: Retrosynthetic approach to polycyclic sulfones.

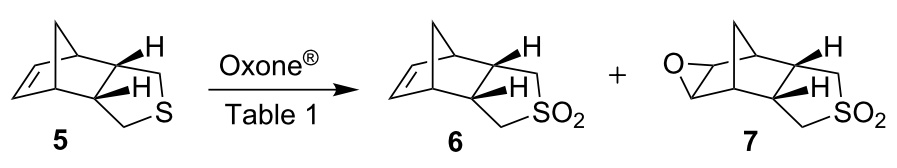

Scheme 1: Preparation of the sulfone 6 via oxidation.

Table 1: Different reaction conditions used to improve the yield of the sulfone 6

\begin{tabular}{llll} 
Entry & Reaction conditions & 6 yield [\%] & 7 yield [\%] \\
\hline 1 & Oxone $^{\circledR}\left(3\right.$ equiv), $\mathrm{MeOH}, \mathrm{H}_{2} \mathrm{O}, 0^{\circ} \mathrm{C}, 22 \mathrm{~h}$ & 29 & 40 \\
2 & Oxone $^{\circledR}(\mathbf{2 . 5}$ equiv $), \mathrm{MeOH}, \mathrm{H}_{2} \mathrm{O},-5{ }^{\circ} \mathrm{C}, \mathbf{6} \mathrm{h}$ & $\mathbf{8 9}$ & 15 \\
3 & Oxone $^{\circledR}(2.5$ equiv $), \mathrm{MeOH}, \mathrm{H}_{2} \mathrm{O},-5^{\circ} \mathrm{C}, 5.5 \mathrm{~h}$ & 83 & 5 \\
4 & $\mathrm{Oxone}^{\circledR}(2.2$ equiv $), \mathrm{MeOH}, \mathrm{H}_{2} \mathrm{O},-8{ }^{\circ} \mathrm{C}, 4.5 \mathrm{~h}$ & 82 & 71 \\
5 & Oxone $^{\circledR}(2$ equiv $), \mathrm{MeOH}, \mathrm{H}_{2} \mathrm{O},-20^{\circ} \mathrm{C}, 5 \mathrm{~h}$ & 5
\end{tabular}


equivalents of allyl bromide and $n$-BuLi produced the diallylated sulfone $\mathbf{2 a}$ in $80 \%$ yield and the monoallylated compound $\mathbf{8 a}$ in $10 \%$ yield (Table 2, entry 1a) [35] along with a minor amount (3\%) of triallylated sulfone 9 (Scheme 2). However, with an excess amount of base ( 5 equiv) and allyl bromide the diallylated sulfone $\mathbf{2 a}$ was isolated as a major product and the triallylated sulfone 9 in $6 \%$ yield (Table 2, entry $1 \mathrm{~b}$ ). Later, the monoallylated sulfone $\mathbf{8 a}$ has been converted to the desired diallyl compound 2 a $(88 \%)$ under similar reaction conditions. The structures of the diallyl (2a) and triallyl (9) sulfones have been confirmed by ${ }^{1} \mathrm{H}$ and ${ }^{13} \mathrm{C}$ NMR spectral data and further supported by HRMS data. In addition, the structure and stereochemistry of the allyl groups present in compound 2a have been confirmed by single-crystal X-ray diffraction studies and this data clearly indicated that the allylation had occurred at $\alpha$-position of the sulfone moiety and the two allyl groups are in cis-arrangement with each other [3537].

Analogously, the alkenylation of sulfone 6 was optimized with other electrophiles and the results are summarized in Table 2 (entries 2-4). In this regard, sulfone 6 was butenylated with 4-bromo-1-butene and $n$-BuLi in the presence of HMPA at $-74{ }^{\circ} \mathrm{C}$ to rt to deliver the monobutenylated sulfone $8 \mathbf{b}$ in $75 \%$ yield. Surprisingly, here a minor amount of the desired dibutenylated sulfone $\mathbf{2 b}(21 \%)$ was isolated (Table 2, entry 2). However, the monobutenylated sulfone $\mathbf{8 b}$ can be converted to the dibutenylated sulfone $\mathbf{2} \mathbf{b}$ under similar conditions. Next, the same synthetic sequence has been extended to the dipentenyl and the dihexenyl sulfone derivatives. Thus, treatment of sulfone 6 with 5-bromo-1-pentene and $n$-BuLi using HMPA at $-78{ }^{\circ} \mathrm{C}$ to rt (Table 2 , entry 3 ) gave the desired dipentenylated sulfone 2c (57\%) and a minor amount of monopentenylated sulfone 8 c (5\%).

Similarly, we synthesized the hexenyl sulfone derivatives $\mathbf{8 d}$ and $\mathbf{2 d}$ by treating compound $\mathbf{6}$ with 6-bromo-1-hexene using HMPA and $n$-BuLi at $-78{ }^{\circ} \mathrm{C}$. The desired dihexenylated sulfone $2 \mathrm{~d}$ has been furnished in $75 \%$ yield along with monohexenyl sulfone derivative $8 \mathbf{d}$ ( $9 \%$, Table 2, entry 4). Based on these optimization studies, it was concluded that it is necessary to use the appropriate number of equivalents of the alkenyl bromide and the suitable base to generate the dialkenylated products (Table 2 and Scheme 2).

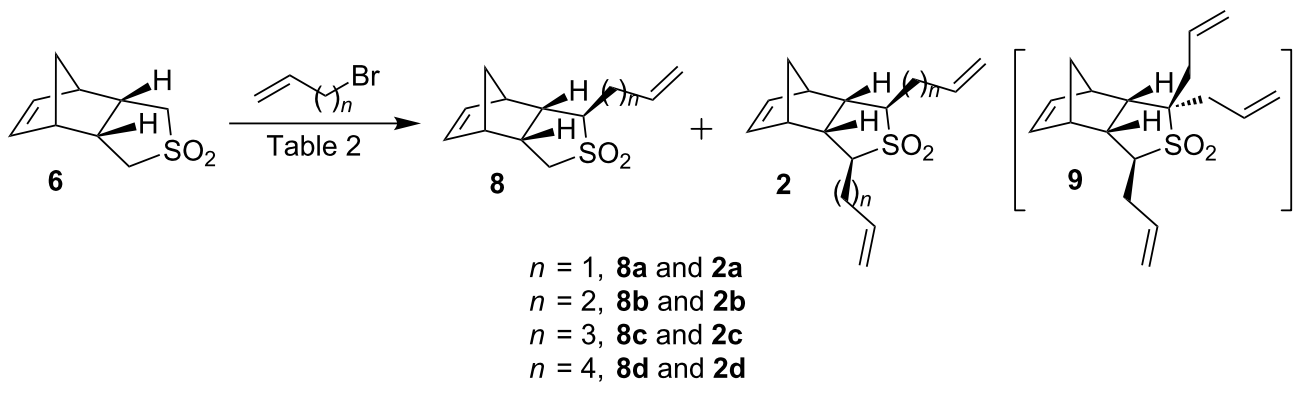

Scheme 2: Synthesis of alkenylated sulfone derivatives.

Table 2: Optimized reaction conditions to realize mono and dialkenylated sulfones.

\begin{tabular}{|c|c|c|c|c|}
\hline Entry & $n$ & Reaction conditions & $\begin{array}{l}\text { Monoalkenylated product } \\
\text { yield [\%] }\end{array}$ & $\begin{array}{l}\text { Dialkenylated product } \\
\text { yield [\%] }\end{array}$ \\
\hline $1 \mathrm{a}$ & 1 & $\begin{array}{l}\text { allyl bromide ( } 3 \text { equiv), } n \text {-BuLi } \\
\text { THF, }-75^{\circ} \mathrm{C} \text { to rt, } 25 \mathrm{~h}\end{array}$ & $8 \mathbf{a}(10)$ & $2 a(80) \& 9^{a}(3)$ \\
\hline $1 b$ & & $\begin{array}{l}\text { allyl bromide (10 equiv), } n \text {-BuLi } \\
\mathrm{THF},-58^{\circ} \mathrm{C} \text { to rt, } 26 \mathrm{~h}\end{array}$ & $8 \mathbf{a}(0)$ & $2 a(80) \& 9^{a}(6)$ \\
\hline 2 & 2 & $\begin{array}{l}\text { 4-bromo-1-butene ( } 3 \text { equiv), } n \text {-BuLi } \\
\text { HMPA, THF, }-74^{\circ} \mathrm{C} \text { to rt, } 20 \mathrm{~h}\end{array}$ & $8 \mathrm{~b}\left(75^{\mathrm{b}}\right)$ & $2 \mathbf{b}\left(21^{b}\right)$ \\
\hline 3 & 3 & $\begin{array}{l}\text { 5-bromo-1-pentene ( } 2.5 \text { equiv), } n \text {-BuLi } \\
\text { HMPA, THF, }-78^{\circ} \mathrm{C} \text { to rt, } 17.5 \mathrm{~h}\end{array}$ & $8 c(5)$ & 2c (57) \\
\hline 4 & 4 & $\begin{array}{l}\text { 6-bromo-1-hexene ( } 2.8 \text { equiv), } n \text {-BuLi } \\
\text { HMPA, THF, }-78^{\circ} \mathrm{C} \text { to rt, } 17 \mathrm{~h}\end{array}$ & $8 d(9)$ & 2d (75) \\
\hline
\end{tabular}

aTriallylated product, ${ }^{b_{\text {isolated }}}$ yield based on starting material recovered. 
After the successful synthesis of various dialkenyl sulfone derivatives $\mathbf{2 a}-\mathbf{d}$, we focussed our attention towards the RRM step. Initially, the diallyl sulfone 2a ( $\sim 0.0141 \mathrm{M}$ solution in dry $\mathrm{CH}_{2} \mathrm{Cl}_{2}$ ) was subjected to RRM using G-I catalyst in the presence of ethylene gas in refluxing $\mathrm{CH}_{2} \mathrm{Cl}_{2}$ to get the tetracyclic sulfone 1a, however, we isolated the tricyclic sulfone 10 in $48 \%$ yield. When the G-I catalyst was replaced with G-II a complex mixture of products was observed as indicated by ${ }^{1} \mathrm{H}$ and ${ }^{13} \mathrm{C}$ NMR spectral data. Later, compound 10 was treated with conventional Grubbs catalysts under different reaction conditions (Table 3) to obtain the RRM product 1a (Scheme 3). Unfortunately, the expected compound 1a was not obtained. The strain present in the trans-fused compound 1a may be responsible for its absence in the RRM sequence.

Interestingly, dibutenyl sulfone $\mathbf{2 b}(\sim 0.0034 \mathrm{M}$ solution in toluene) smoothly underwent RRM with Grubbs $2^{\text {nd }}$ generation (G-II) catalyst in the presence of ethylene in refluxing toluene to produce the anticipated tetracyclic sulfone $\mathbf{1 b}(97 \%)$ (Scheme 4). The sulfone $\mathbf{1 b}$ has been characterized by ${ }^{1} \mathrm{H}$ and ${ }^{13} \mathrm{C}$ NMR and DEPT-135 spectral data including HRMS data.
Next, the RRM of dipentenyl sulfone $2 \mathbf{c}(\sim 0.0031$ M solution in toluene) was carried out under similar reaction conditions to furnish 1c. Interestingly, the tricyclic sulfone $\mathbf{1 1}$ was isolated in $60 \%$ along with the expected tetracyclic sulfone 1c (32\%) and a minor amount of ring-opened product 12 (6\%, Scheme 5). A complex mixture of products was obtained when compound $\mathbf{2 c}$ was exposed to the metathesis catalyst for a longer period of time as indicated by ${ }^{1} \mathrm{H}$ and ${ }^{13} \mathrm{C}$ NMR spectral data.

Analogously, dihexenyl sulfone 2d $(\sim 0.0024 \mathrm{M}$ solution in toluene) was treated with G-II catalyst to deliver the RRM product in the presence of ethylene in refluxing toluene. In this regard, only ring-opened sulfone $\mathbf{1 3}$ was produced in $88 \%$ yield (Scheme 6) and no cyclized product was observed. Presumably, this observation may be explained on the basis that the ninemembered ring product was not formed due to the unfavourable steric interactions involved.

\section{Conclusion}

Several interesting polycyclic sulfone derivatives were designed and assembled involving RRM. The RRM outcome of various
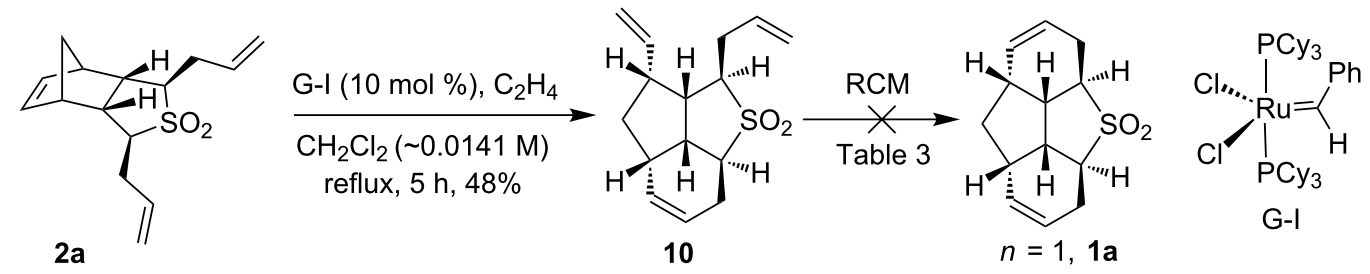

Scheme 3: Synthesis of 10 by RRM of $2 a$.

\begin{tabular}{|c|c|c|}
\hline Entry & Conditions & Result \\
\hline 1 & G-I $(10 \mathrm{~mol} \%), \mathrm{C}_{2} \mathrm{H}_{4}, 19 \mathrm{~h}$ & $\mathrm{SM}^{\mathrm{a}}$ recovered \\
\hline 2 & G-II (10 mol \%), Ti(OiPr $)_{4}, \mathrm{C}_{2} \mathrm{H}_{4}, 24 \mathrm{~h}$ & No product ${ }^{\mathrm{b}}$ \\
\hline 3 & $\mathrm{HG}-\mathrm{II}^{\mathrm{C}}(10 \mathrm{~mol} \%), \mathrm{Ti}(\mathrm{OiPr})_{4}, \mathrm{C}_{2} \mathrm{H}_{4}, 24 \mathrm{~h}$ & No product ${ }^{b}$ \\
\hline
\end{tabular}

aStarting material. bSM not recovered, ${ }^{\mathrm{C}} \mathrm{Hoveyda-Blechert-Grubbs}$ catalyst.

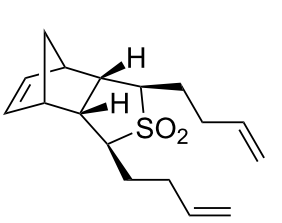

2b

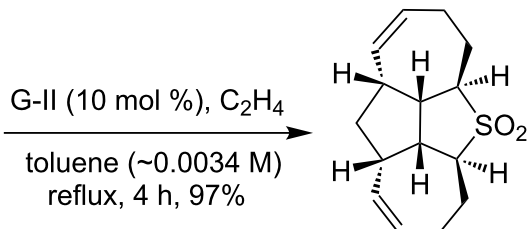

$1 \mathrm{~b}$

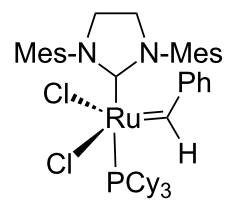

G-II 


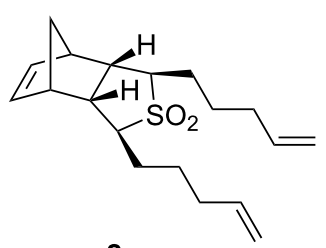

2c

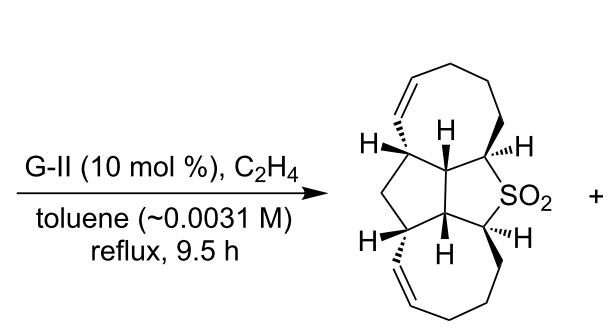

1c $(32 \%)$

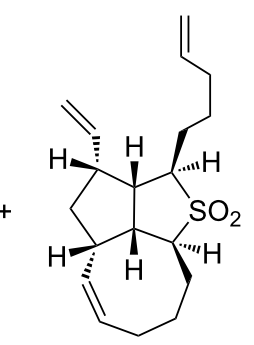

$11(60 \%)$

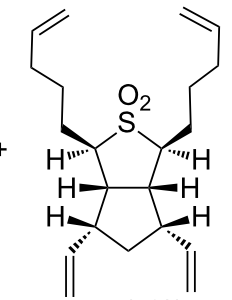

$12(6 \%)$

Scheme 5: RRM of the dipentenyl sulfone 2c.
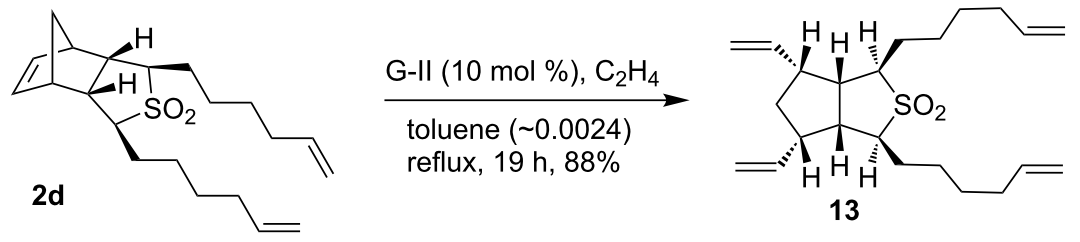

Scheme 6: RRM of the dihexenyl sulfone $2 d$

sulfones (2a-d) depends on the length of the alkenyl chain. In this context, the dibutenyl sulfone derivative $\mathbf{2} \mathbf{b}$ is the mostpromising candidate for the RRM protocol. In other instances, for example with propenyl analogue 2a the partial ring-closing product $\mathbf{1 0}$ was obtained. With substrate $\mathbf{2 c}$, the eightmembered RRM compound $\mathbf{1 c}$ was formed as a minor product and partial ring-closing compound $\mathbf{1 1}$ as a major product. With substrate 2d, only ring-opened product $\mathbf{1 3}$ was produced. Interestingly, we demonstrated trans-ring junction products are possible in the RRM protocol. It is clear that RRM has a unique place in olefin metathesis [38-45] and further interesting examples are expected in future.

\section{Supporting Information}

\section{Supporting Information File 1}

Detailed experimental procedures, characterization data and copies of ${ }^{1} \mathrm{H},{ }^{13} \mathrm{C}$ NMR and HRMS spectra for all new compounds.

[http://www.beilstein-journals.org/bjoc/content/ supplementary/1860-5397-11-148-S1.pdf]

\section{Acknowledgements}

We thank the Department of Science and Technology (DST), New Delhi for the financial support and the Sophisticated Analytical Instrument Facility (SAIF), IIT-Bombay for recording spectral data. S.K. thanks the Department of Science and Technology for the award of a J. C. Bose fellowship. R.G. thanks the University Grants Commission (UGC), New Delhi for the award of a research fellowship.

\section{References}

1. Alba, A.-N. R.; Companyó, X.; Rios, R. Chem. Soc. Rev. 2010, 39, 2018-2033. doi:10.1039/B911852G

2. Meadows, D. C.; Gervay-Hague, J. Med. Res. Rev. 2006, 26, 793-814. doi:10.1002/med.20074

3. Bäckvall, J.-E.; Chinchilla, R.; Nájera, C.; Yus, M. Chem. Rev. 1998, 98, 2291-2312. doi:10.1021/cr970326z

4. García Ruano, J. L.; Alemán, J.; Parra, A.; Marzo, L. Eur. J. Org. Chem. 2014, 1577-1588. doi:10.1002/ejoc.201301483

5. Alonso, D. A.; Fuensanta, M.; Nájera, C.; Varea, M. Phosphorus, Sulfur Silicon Relat. Elem. 2005, 180, 1119-1131. doi:10.1080/10426500590910657

6. Roy, K.-M. Sulfones and Sulfoxides. Ullmann's Encyclopedia of Industrial Chemistry; Wiley-VCH: Weinheim, 2000. doi:10.1002/14356007.a25_487

7. Kotha, S.; Ali, R. Tetrahedron Lett. 2015, 56, 2172-2175. doi:10.1016/j.tetlet.2015.03.021

8. Kotha, S.; Ali, R. Tetrahedron 2015, 71, 1597-1603. doi:10.1016/j.tet.2015.01.009

9. Kotha, S. Acc. Chem. Res. 2003, 36, 342-351. doi:10.1021/Ar020147q

10. Harvey, J. E.; Bartlett, M. J. Chem. N. Z. 2010, 74, 63-69. And references cited therein.

11. Metz, P.; Fleischer, M.; Fröhlich, R. Tetrahedron 1995, 51, 711-732. doi:10.1016/0040-4020(94)00969-2

12. Barbarella, G.; Cinquini, M.; Colonna, S. J. Chem. Soc., Perkin Trans. 1 1980, 1646-1649. doi:10.1039/P19800001646

13. Kotha, S.; Bandi, V. Heterocycles 2015, 90, 226-237. doi:10.3987/Com-14-S(K)9 
14. Kotha, S.; Khedkar, P. J. Org. Chem. 2009, 74, 5667-5670. doi:10.1021/jo900658z

15. Holub, N.; Blechert, S. Chem. - Asian J. 2007, 2, 1064-1082. doi:10.1002/asia.200700072 And references cited therein

16. Vincent, G.; Kouklovsky, C. Chem. - Eur. J. 2011, 17, 2972-2980. doi:10.1002/chem.201002558

17. Nolan, S. P.; Clavier, H. Chem. Soc. Rev. 2010, 39, 3305-3316. doi:10.1039/B912410c

18. Clavier, H.; Broggi, J.; Nolan, S. P. Eur. J. Org. Chem. 2010, 937-943. doi:10.1002/ejoc.200901316

19. Tsao, K.-W.; Devendar, B.; Liao, C.-C. Tetrahedron Lett. 2013, 54, 3055-3059. doi:10.1016/j.tetlet.2013.03.142

20. Standen, P. E.; Kimber, M. C. Tetrahedron Lett. 2013, 54, 4098-4101. doi:10.1016/j.tetlet.2013.05.112

21. Li, J.; Lee, D. Chem. Sci. 2012, 3, 3296-3301. doi:10.1039/C2sc20812a

22. Imhof, S.; Blechert, S. Synlett 2003, 609-614. doi:10.1055/s-2003-38367

23. Arjona, O.; Csákÿ, A. G.; Plumet, J. Eur. J. Org. Chem. 2003, 611-622. doi:10.1002/ejoc.200390100

24. Nguyen, N. N. M.; Leclère, M.; Stogaitis, N.; Fallis, A. G. Org. Lett. 2010, 12, 1684-1687. doi:10.1021/Ol100150f

25. Datta, R.; Bose, S.; Viththlbhai, P. B.; Ghosh, S. Tetrahedron Lett. 2014, 55, 3538-3540. doi:10.1016/j.tetlet.2014.04.091

26. Lam, J. K.; Pham, H. V.; Houk, K. N.; Vanderwal, C. D J. Am. Chem. Soc. 2013, 135, 17585-17594. doi:10.1021/ja409618p

27. Kotha, S.; Ravikumar, O. Tetrahedron Lett. 2014, 55, 5781-5784. doi:10.1016/j.tetlet.2014.08.108

28. Kotha, S.; Ravikumar, O. Eur. J. Org. Chem. 2014, 5582-5590. doi:10.1002/ejoc.201402273

29. Goll, J. M.; Fillion, E. Organometallics 2008, 27, 3622-3625. doi:10.1021/Om800390w

30. Wilcox, C. F., Jr.; Craig, R. R. J. Am. Chem. Soc. 1961, 83, 3866-3871. doi:10.1021/ja01479a030

31. Zhang, M.; Flynn, D. L.; Hanson, P. R. J. Org. Chem. 2007, 72, 3194-3198. doi:10.1021/Jo0620260

32. Trost, B. M.; Curran, D. P. Tetrahedron Lett. 1981, 22, 1287-1290. doi:10.1016/S0040-4039(01)90298-9

33. Bloch, R.; Abecassis, J. Tetrahedron Lett. 1982, 23, 3277-3280. doi:10.1016/S0040-4039(00)87591-7

34. Bloch, R.; Abecassis, J.; Hassan, D. Can. J. Chem. 1984, 62, 2019-2024. doi:10.1139/V84-345

35. Kotha, S.; Gunta, R. Acta Crystallogr., Sect. E 2014, 70, 01163-01164. doi:10.1107/S1600536814022053

36. Bloch, R.; Abecassis, J. Synth. Commun. 1985, 15, 959-963. doi:10.1080/00397918508076826

37. Bloch, R.; Abecassis, J. Tetrahedron Lett. 1983, 24, 1247-1250. doi:10.1016/S0040-4039(00)81626-3

38. Grubbs, R. H. Handbook of Metathesis, 1st ed.; Wiley-VCH: Weinheim, 2003.

39. Kotha, S.; Sreenivasachary, N. Indian J. Chem., Sect. B 2001, 40, 763-780.

40. Kotha, S.; Lahiri, K. Synlett 2007, 2767-2784. doi:10.1055/s-2007-990954

41. Kotha, S.; Mandal, K. Chem. - Asian J. 2009, 4, 354-362. doi:10.1002/asia.200800244

42. Kotha, S.; Misra, S.; Sreevani, G.; Babu, B. V. Curr. Org. Chem. 2013, 17, 2776-2795. doi:10.2174/13852728113179990118
43. Kotha, S.; Meshram, M.; Tiwari, A. Chem. Soc. Rev. 2009, 38, 2065-2092. doi:10.1039/B810094m

44. Kotha, S.; Dipak, M. K. Tetrahedron 2012, 68, 397-421. doi:10.1016/j.tet.2011.10.018

45. Kotha, S.; Krishna, N. G.; Halder, S.; Misra, S. Org. Biomol. Chem. 2011, 9, 5597-5624. doi:10.1039/c1ob05413a

\section{License and Terms}

This is an Open Access article under the terms of the Creative Commons Attribution License

(http://creativecommons.org/licenses/by/2.0), which permits unrestricted use, distribution, and reproduction in any medium, provided the original work is properly cited.

The license is subject to the Beilstein Journal of Organic Chemistry terms and conditions:

(http://www.beilstein-journals.org/bjoc)

The definitive version of this article is the electronic one which can be found at: doi:10.3762/bjoc. 11.148 